European Association for the

Development of Renewable Energies,

Environment and Power Quality (EA4EPQ)
International Conference on Renewable Energies and Power Quality (ICREPQ'11)

Las Palmas de Gran Canaria (Spain), 13th to 15th April, 2011

\title{
Feasibility of wind power generation for the reduction of power costs in residential buildings
}

\author{
Rômulo Monteiro Callado $^{1,2}$, João Reinaldo Imbiriba da Rocha Junior ${ }^{1}$ and Antonio Felisberto P. Amorim ${ }^{1}$ \\ ${ }^{1}$ Department of Electronic Engineering \\ Edson Queiróz Foundation, Fortaleza University \\ Fortaleza, Ceará (Brazil) \\ Phone/Fax number: +5585 88801173/+5585 32244529, e-mail: romulo_callado@,hotmail.com, felisberto@,rdvsa.com.br \\ ${ }^{2}$ Normatel Engenharia Ltda., Fortaleza, Ceará (Brazil) \\ Phone/Fax number: +5585 40061198, e-mail: rmonteiro@normatel.eng.br
}

\begin{abstract}
Introduction: The installation of wind power generators on buildings located in areas with regular winds may be a suitable investment in a renewable power source. Brazil has a high eolic potential, where the annual mean wind speed may reach over eight meters per second. This case study is aimed to assess the economic feasibility of the installation of small wind power plants in urban areas. Methods: This work evaluates a project for the installation of a vertical axis wind turbine in three buildings (15-, 22-, and 26-store) including the following stages: 1) Installation of a real-time power meter in the 15-store unit; 2) Demand analysis of the 26-store building's power consumption; 3) Winds survey along the coast of the State of Ceará; 4) Analysis of the wind turbines available in the market; 5) Simulation aimed to choose the system. Results: Vertical wind power generators offer better conditions of use in urban areas. The turnover time was established to be between four and six years in the three studied units. Conclusions: The installation of a wind power generator on buildings in regions with an adequate eolic regimen reaches a financial return of the investment before the end of the equipment's lifespan.
\end{abstract}

\section{Key words}

Wind power generator, wind energy, power consumption, renewable energy, power plants in urban areas.

\section{Introduction}

Brazil has a great wind power generation potential and Ceará is among the most promising of all its states. The installed capacity in Brazil by the end of 2007 was only 247 megawatts (MW), while Portugal had 2,150 MW. The estimation is that the Brazilian potential could go beyond $143 \mathrm{GW}$. In the UK, the Sustainable Development Commission [1], a commission that deals with environmentally sustainable projects, stated that most of the wind generation growth in Great Britain comes from small producers interested in reducing their power bills and who are also concerned with the environment. In Ceará there is a great potential for the application of the English model in regions with winds exceeding five meters/second. This case study aims to show the economic feasibility of installing small wind turbines in urban areas for the private use of the generated electricity [2]. Several factors are essential in the choice of vertical axis turbines. Vertical-axis turbines are ideal for environments with high turbulence, have a low noise generation, high aerodynamic efficiency, are practically free of any vibration and have a low maintenance cost, while being safe in the event of a transient excess of winds.

\section{Materials and Methods}

This is a case study for the implementation of a vertical axis wind turbine on the roof of buildings in the city of Fortaleza.

\section{A. Characterization of the sample}

Simulations were conducted on two residential units: Unit I (15- store buildings), Unit II (23-store buildings) and Unit III (commercial 23-store building). The heights of the buildings were taken with a GPS (Global Positioning System).

\section{B. Power demand profile analysis}

A real-time, Embrasul RE 1000/TM power meter was installed at the entrance of the electric company's triphasic power meter in Unit I, recording current and voltage measurements at 30 -second intervals throughout the day for one week. The demand of the Unit II was proportionally adjusted from that of the first building. The profile of the Unit III was requested from the electric 
company, which keeps the real-time records of mediumvoltage consumers. Data corresponding to two months were obtained, with readings done at 15 -minute intervals.

\section{Winds regimen survey for the coast of Ceará}

An analysis of wind currents along the year was carried out by means of wind measurements maps provided by the Department of Infrastructure of the State of Ceará (SEINFRA) [3]. Wind seasonality was provided by Companhia Hidroelétrica do Vale do Sao Francisco [4]. The projected monthly hourly averages of the winds were obtained from the Embuaca and Canoa Quebrada-Aracati wind farms, as provided by Alubar Embuaca Geradora de Energia Eólica SA.

\section{Choice of the wind power generator}

The complete system, composed of a turbine, tower, rectifiers and power inverters from continuous to alternated power will be purchased from a domestic or foreign company.

\section{E. Economic feasibility of the project}

Economic feasibility obtained through the analysis of the actual cost of electric power per unit, the cost of the chosen wind power generation system, the capacity to generate power with a turbine appropriate to supply the demand of the unit in question. The curve of daily average winds for each month of the year in Fortaleza and the power curve of the chosen wind turbine will render the projected daily electric power generation capacity. This analysis was done considering the co-generation of power with the local electric company in order to simplify the enterprise. In times of high demand and lack of winds, the electric company would provide power to the unit, while whenever there is an excess generation of instant power, it would be discharged on the electric company's grid. This form of power usage needs the system to be reliable and the generation itself to be perfectly synchronized with the layout of the electric company, so as not to damage the grid or the end users. This model avoids the need of batteries to withstand times of high demand and enables the sale of any surplus energy, which can generate a profit for the unit. We performed a simulation for each studied unit using the prices of the Brazilian market.

\section{Results}

\section{A. Sample characterization}

See Table I.

\section{B. Power demand profile analysis}

An hourly average was calculated for weekdays and weekends, based on data obtained from Unit I. The highest peak load was recorded during the operation of the elevators and the pumping of water to the water tank. A daily profile was built, observing the baseline and nighttime demand and the two relevant peaks (Figure 1).
Table 1. Sample characterization

\begin{tabular}{|l|c|c|c|}
\hline Characteristics: & \multicolumn{3}{|c|}{ Unit } \\
\hline Type & I & II & III \\
\hline Rooftop altitude (m) & 100 & 120 & 120 \\
\hline Number of floors & 15 & 23 & 23 \\
\hline Units/floor & 1 & 3 & 8 \\
\hline Total units & 15 & 69 & 184 \\
\hline Elevators & 2 & 3 & 7 \\
\hline Water pump & 1 & 1 & 2 \\
\hline Diesel generator* & 1 & 1 & 1 \\
\hline Gate engine & 1 & 2 & 3 \\
\hline Pool engine & 1 & 0 & 0 \\
\hline Lighting in common areas & 40 & 60 & 80 \\
\hline Motion sensor & \multicolumn{3}{|l}{} \\
\hline Yes & 20 & 30 & 40 \\
\hline No & 20 & 30 & 40 \\
\hline Class & 15 & 69 & 184 \\
\hline Single-phase & 1 & 1 & $1 * *$ \\
\hline Triphasic &
\end{tabular}

$\mathrm{m}=$ meters; $*=$ Used during power outages to supply emergency power to elevators and illumination of common areas; $* *=$ medium voltage.

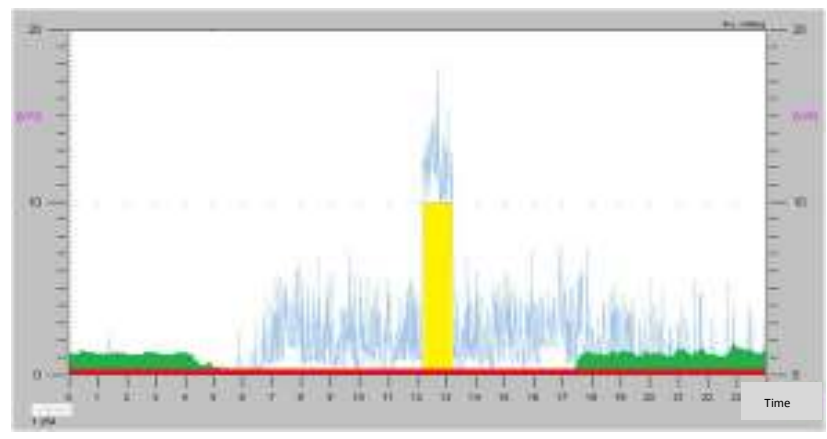

Fig. 1. Residential demand daily profile.

Baseline demand

Nighttime demand

Water pump

Operation of elevators

The unit's demand analysis during the year was based on an average for a weekday and for a weekend day. Demand related to the pumping of water was excluded from said direct averages, since the hourly averages would be strongly affected by the time in which the water tank was filled during the sampled week. To compensate for this procedure, a weekly water pumping frequency was considered (two fills per weekend and eight during the five weekdays) and such demand was distributed over the hours of each day. This demand was used for the simulations of the unit, which has an average monthly demand of 2,262 kWh. Figure 2 shows the obtained load curve. The hourly demand of the Unit II, which has an average monthly demand of 4,904 kWh, was proportionally extrapolated from the Unit I. The calculations for the Unit III were performed as per the same methods used for the residential units with data supplied by the electric company. The unit average monthly demand is $10,879 \mathrm{kWh}$; resulting the load curve shown in Figure 3. 


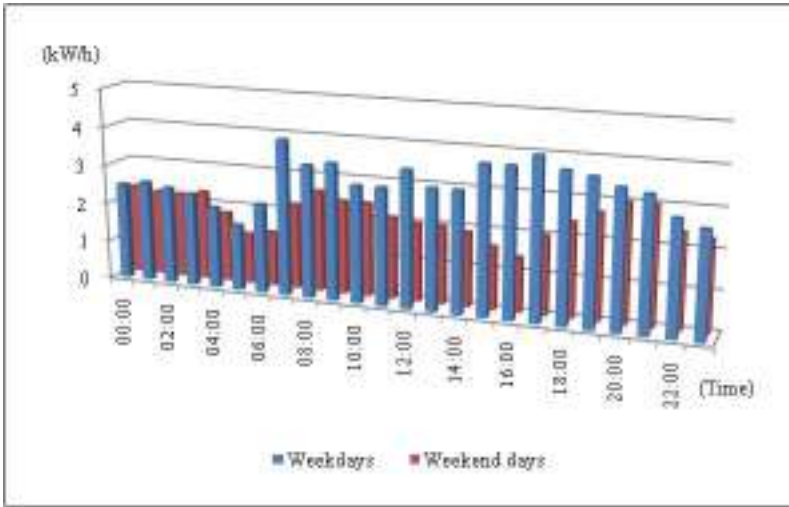

Fig. 2. Load curve of Unit I.

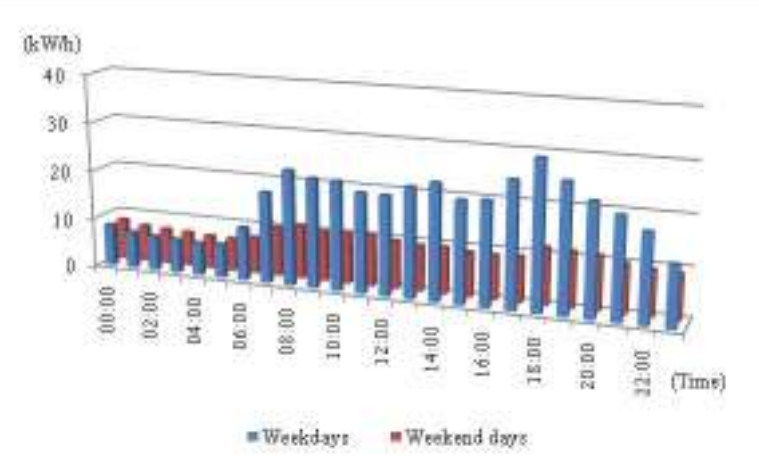

Fig. 3. Daily load curve of the Unit III.

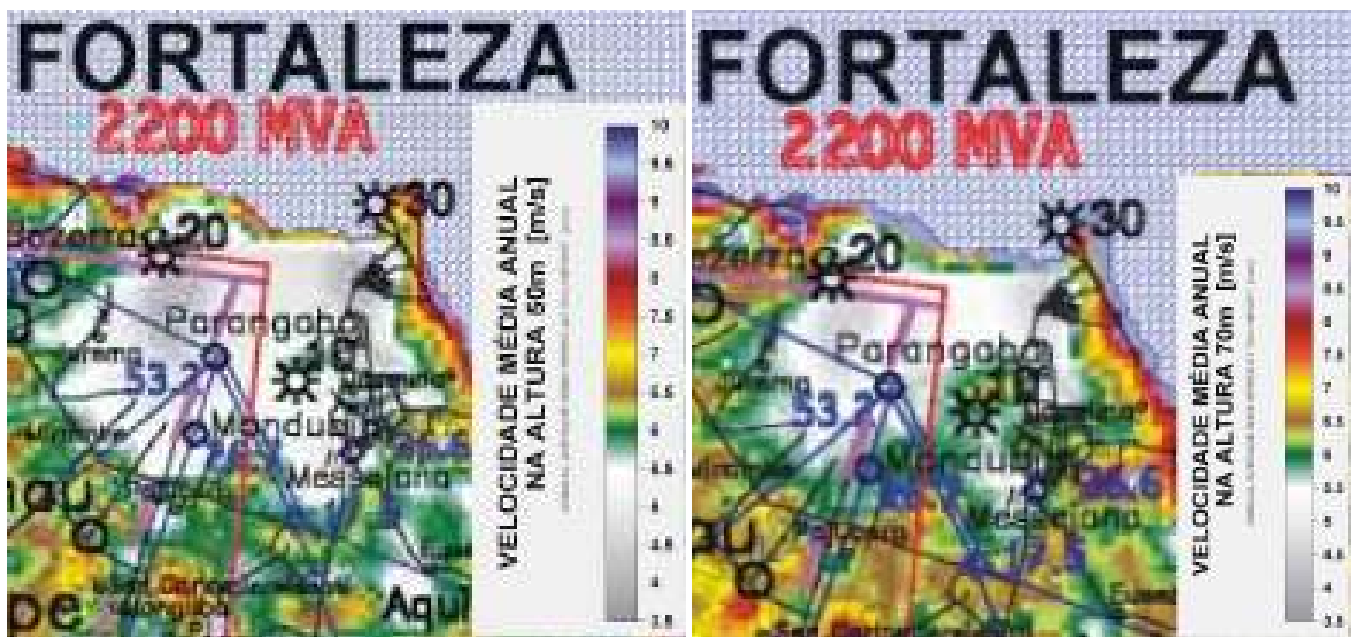

Fig. 4. Average annual speed of wind at the heights of 50 and 70 meters (SEINFRA, 2009).

\section{Wind survey in the coast of Ceará}

1) Wind speed: The available information is in according to the annual average wind speeds measured in Fortaleza at the altitudes of 50 and 70 meters provided by SEINFRA (Figure 4).

2) Wind seasonality: Data were obtained from studies made by CHESF for potential wind power generation along $10 \%$ of the coastline of the State of Ceará [4].

3) Calculations of projected wind annual average: Considering the production of the wind farms along the coast of Ceará, it appears that the year is divided into two wind seasons: January to June, with medium-low winds, and July to December, with strong winds. This study used data from two measurement towers, located in the district of Embuaca-Trairi (Figure 5) and in Canoa Quebrada-Aracati (Figure 6), in order to prepare the daily profile for each month. Four months of the year were analyzed in each tower, which represents the annual distribution of winds in the coast of Ceará. With the available wind information on the coast it was possible to generate data on wind speed per hour for a normal day of each month of the year (Figure 7). Comparing the obtained results to the Wind

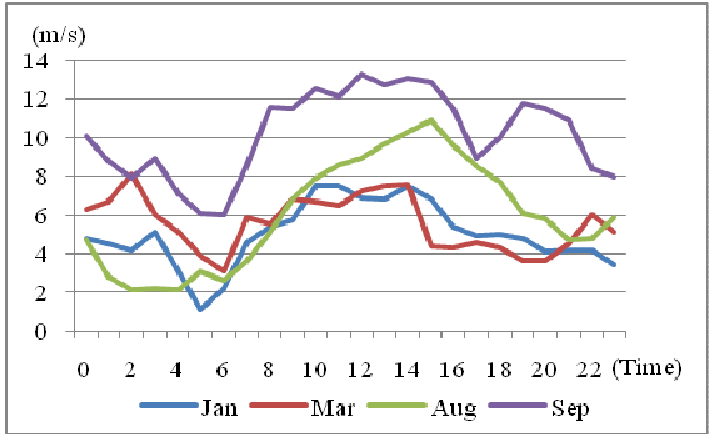

Fig. 5. Monthly averages of the winds in the Embuaca wind farm. Source: Alubar Embuaca Geradora Energia Eólica S.A.

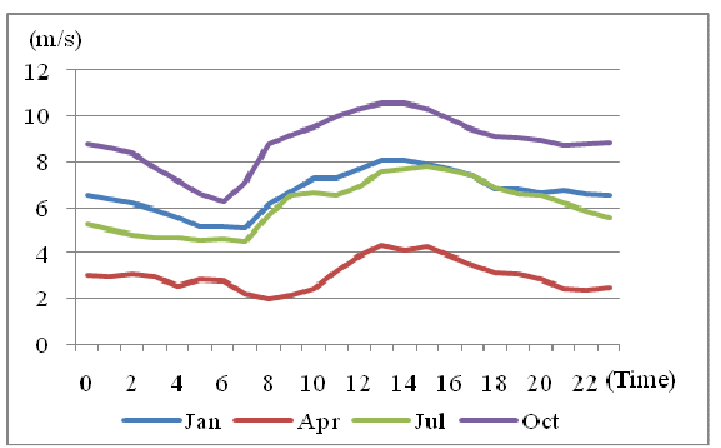

Fig. 6. Monthly averages of the winds in the Canoa Quebrada wind farm. Source: Aracati Aeolis Geração de Energia Ltda. 


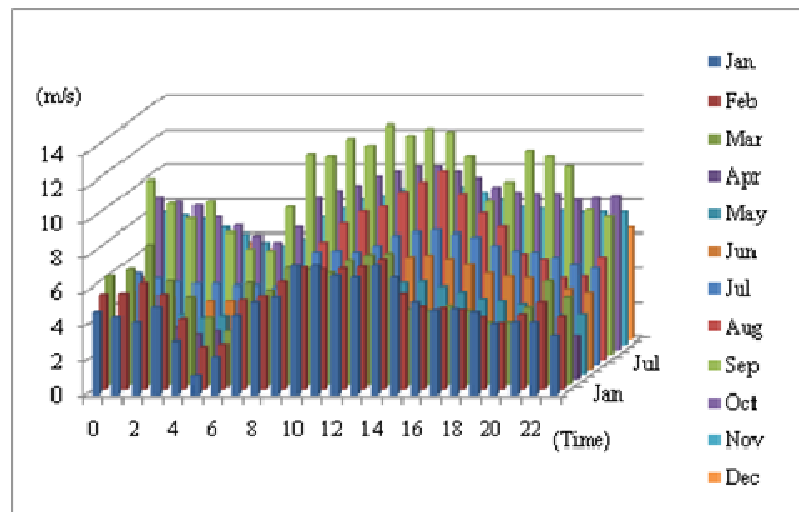

Fig. 7. Annual projection of wind curves in the coast of Ceará (hourly average of one day each month).

maps of 50 and 70 meters high provided by SEINFRA (Figure 4) a speed average elevation is identified as expected at 100 meters altitudes from the studied units.

4) Choice of a wind power generator: We analyzed the equipment offered by Green Master Energy [5] and Kino Wind Turbines [6]. The wind power generator chosen for each unit is specified in the simulations.

D. Economic feasibility of wind projects installed on rooftops

1) Calculation of the wind turbine's daily electric power output: With the result of the daily winds average curve for each month of the year and the power curve of each generator, the electricity generation capacity in a given month was projected. As an example, the installation of a Kino wind turbine with a $10 \mathrm{~kW}$ power rating was considered, with the projected monthly results shown in Figure 8.

2) Projections of the energy produced by the wind turbine compared to the power demand of the unit: In the annual simulation with a $10 \mathrm{~kW}$ Kino wind turbine, weekdays demand data from the residential unit were used, which has an average monthly demand of 2,262 kWh. Figure 9 shows the monthly power produced by the wind turbine, supplemented by that supplied by the electric company and the surplus power produced by the wind turbine at the times in which the unit is not consuming that load that would be fed to the grid. The average monthly demand of Unit I was estimated to be 74,353 kilowatts.

3) Reduction of electric power costs: Table 2 shows a monthly summary of the economic simulation in local currency. The values of the Surplus column refer to the generated wind power not consumed by the unit and delivered to the distributor's grid for half the price charged to the end user. The Company column refers to the estimate of the unit's power bill throughout the year, after the installation of the wind turbine. The Wind turbine column shows

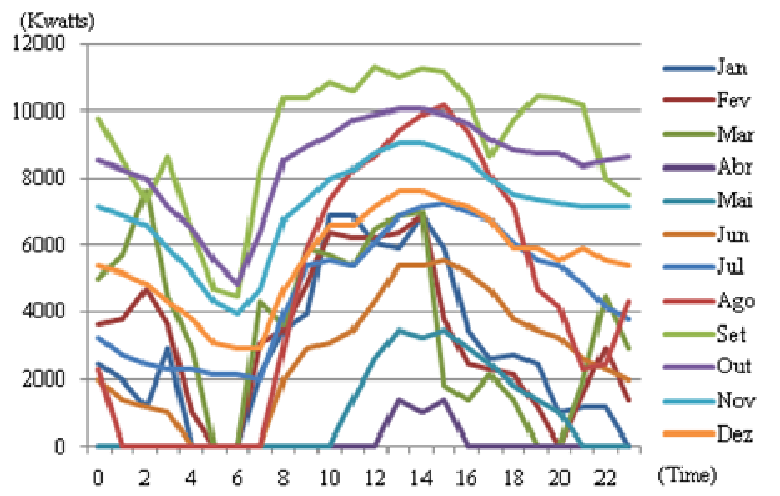

Fig. 8. Monthly projection of the daily power generation average (Kino $10 \mathrm{~kW})$.

the value of the generated wind power if it were sold to the unit at $70 \%$ of the purchase price charged by the electric company.

4) Investments for the purchase of the wind system and turnover time: The cost of equipment installation and its accessories, which varies according to the building due to the reforms and adjustments required on each site, should be considered in the deployment of a wind turbine on building rooftops in a metropolitan area:. The simulations shown in Table 3 refer only to the turnover time for the acquisition of a wind power system.

Table 2. Simulation for the values paid for electric power in Unit I with a Kino $10 \mathrm{~kW}$ wind turbine, in local currency (R\$/month)

\begin{tabular}{|l|r|r|r|r|}
\hline Month & $\begin{array}{c}\text { Total } \\
\text { demand }\end{array}$ & \multicolumn{1}{c|}{ Surplus } & Company & $\begin{array}{r}\text { Wind } \\
\text { generator }\end{array}$ \\
\hline Jan & 1294.98 & 214.58 & 368.92 & 648.24 \\
\hline Feb & 1169.66 & 225.26 & 276.26 & 625.38 \\
\hline Mar & 1294.98 & 345.39 & 318.10 & 683.82 \\
\hline Apr & 1253.21 & 0.00 & 1145.74 & 75.23 \\
\hline May & 1294.98 & 18.35 & 757.60 & 376.17 \\
\hline Jun & 1253.21 & 121.13 & 234.98 & 712.76 \\
\hline Jul & 1294.98 & 402.33 & 30.12 & 885.41 \\
\hline Aug & 1294.98 & 523.23 & 292.69 & 701.60 \\
\hline Sep & 1253.21 & 1419.02 & 0.00 & 877.25 \\
\hline Oct & 1294.98 & 1268.89 & 0.00 & 906.49 \\
\hline Nov & 1253.21 & 930.95 & 0.00 & 877.25 \\
\hline Dec & 1294.98 & 601.85 & 2.82 & 904.51 \\
\hline
\end{tabular}

Total demand $=$ Monthly consumption values for the unit; Surplus $=$ Value received from the electric company for the power unloaded to the power grid; Company= Values paid for supplementary power supplied by the electric company; Wind turbine $=$ Value of the power generated by the wind turbine and consumed by the unit. 


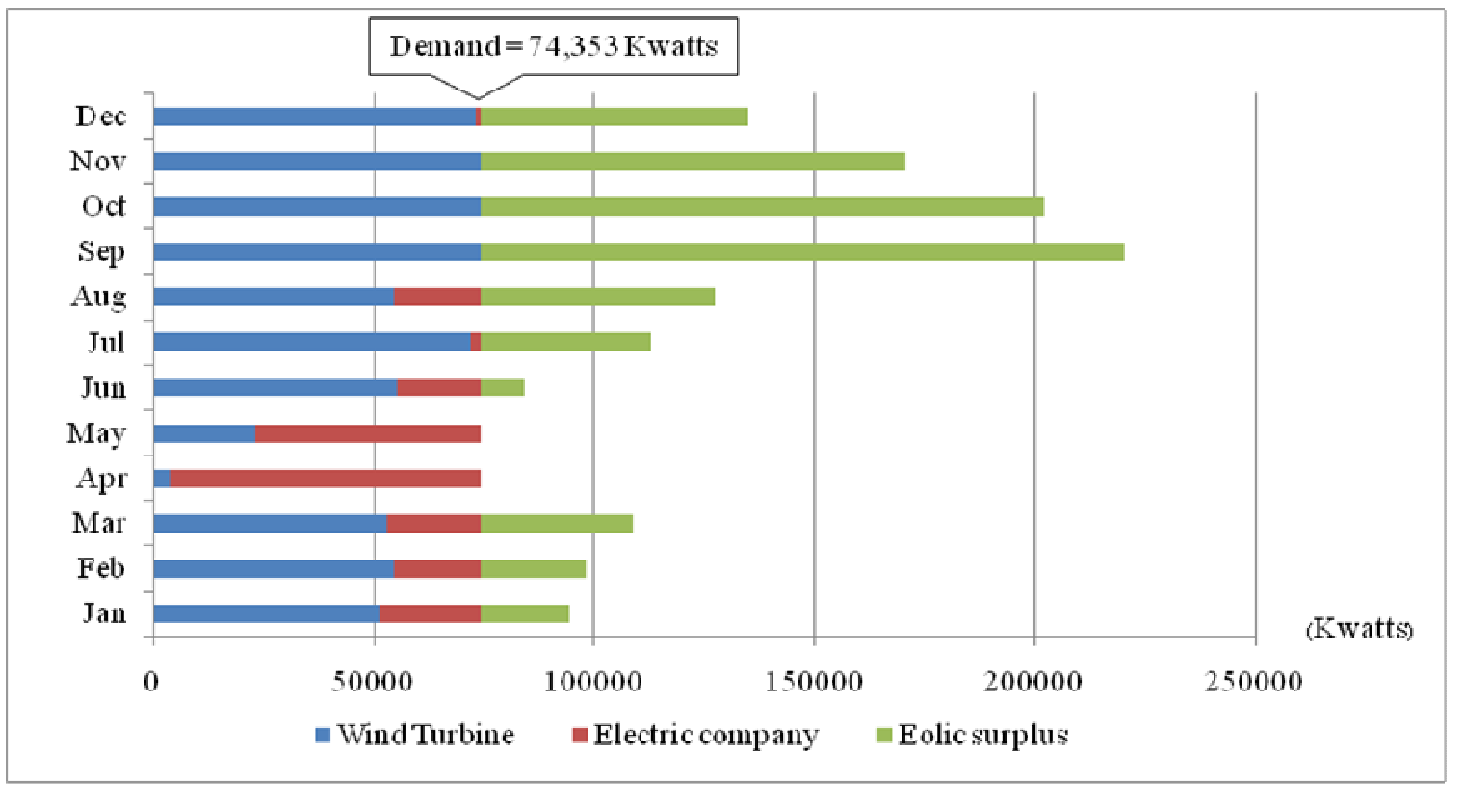

Fig. 9. Simulation of electric power generation and usage in one weekday in Unit I, with a Kino $10 \mathrm{~kW}$ wind turbine. (Expected demand: 74,353 kilowatts).

Table 3. Investment required for the acquisition of a wind power turbine and turnover time

\begin{tabular}{|c|c|c|c|}
\hline \multirow{2}{*}{ Investment analysis } & \multicolumn{3}{|c|}{ Unit } \\
\hline & $\mathrm{I}^{\prime \prime}$ & II" & III $^{\#}$ \\
\hline Wind system model & Kino $10 \mathrm{~kW}$ & Kino $10 \mathrm{~kW}$ & GME $25 \mathrm{~kW}$ \\
\hline Actual annual power demand $(\mathrm{kWh})$ & 25212.00 & 58687.30 & 133415.97 \\
\hline Wind turbine's surplus power/year (kWh) & 19997.45 & 5215.90 & 19278.86 \\
\hline Annual demand supplied by the electric company (kWh) & 5644.55 & 24438.29 & 57723.45 \\
\hline Annual demand supplied by the wind turbine $(\mathrm{kWh})$ & 19467.45 & 34249.00 & 75692.51 \\
\hline Wind turbine's cost (USD) & {$[25000.00]$} & [24820.00] & [37839.00] \\
\hline Wind turbine's cost $(\mathrm{R} \$)^{*}$ & 72250.00 & 72151.74 & 110000.00 \\
\hline Actual cost of power ( $\mathrm{R} \$$ year) & 15247.36 & 35633.41 & 36587.99 \\
\hline Surplus sale (R $\$ /$ year)* & 6070.97 & 1583.48 & 2643.11 \\
\hline Supplementary power from the electric company (R\$/year) & 3427.22 & 14838.30 & 15830.08 \\
\hline Cost of power from the wind turbine, per unit (R\$/year) ${ }^{* *}$ & 8274.09 & 14556.58 & 14530.54 \\
\hline \multicolumn{4}{|l|}{ Turnover time (years) } \\
\hline WITH surplus sale & 4.03 & 3.22 & 4.70 \\
\hline WITHOUT surplus sale & 6.1 & 3.47 & 5.3 \\
\hline
\end{tabular}

$\mathrm{kW}=$ kilowatts; $\mathrm{kWh}=$ kilowatts.hour; " $=\mathrm{kWh}$ price for the end consumer $\mathrm{R} \$ 0.607174$; $\#=\mathrm{kWh}$ price for the end consumer R\$ 0.27424; GME= Green Master Energy; $"=($ USD $1.00=\mathrm{R} \$ 1.70+70 \%$ Brazilian Import Tax $) ; *=50 \%$ end user price charged by the power company; $* *=70 \%$ end user price charged by the power company.

\section{Discussion}

The use of wind-generated power has many positive aspects, which would increase the chances of success of a wind power generation project implemented on rooftops in urban areas: 1 . With the advance of global warming, the generation and use of alternative energy sources that do not produce greenhouse gases should be prioritized; 2 . The wind currents in the state of Ceará are exceptional for a sustainable power generation, as shown by the many wind farms installed along the coast of Ceará; 3. The placement of wind turbines on building rooftops would allow the use of air currents occurring at an altitude of over 100 meters. These currents are much more constant and direct than the currents found at ground level and at 50 to 70 meters. This would allow a larger and more constant power generation in comparison to the production of the same wind turbines installed in other locations. 4. Because they are installed on rooftops, it is not necessary to use large support towers for the turbines, reducing the cost of the project and facilitating 
its maintenance. 5. The end customer is a partner in the project because the power produced by the wind turbine will be consumed by the unit where it is installed. This unit pays high power bills to the electric company. Common wind turbines sell power to electric companies at a price much lower than that paid by the end consumer. Thus, there is a large profit margin per kilowatt compared to existing commercial wind farms. 6 . During much of the day, especially in the early morning, the power demand of the units is very low. The excess energy generated during these periods may be sold to the electric company, turning into a seasonal source of income. 7. With the project up and running, another way of generating income is the sale of carbon credits. Any system exploiting renewable energy sources can generate carbon credits to be traded in the international market with companies and countries that fail to meet their $\mathrm{CO} 2$ emission reduction goals. These credits have a high international value and can be a great showcase for future loans aimed to finance similar projects.

The installation of wind turbines on high buildings provides a financial return prior to the end of the equipment's lifespan, which is of approximately 15 years. In residential units, where there is a demand for low voltage and there are no time-variant prices for the consumed power, optimizing the filling of the water tank at a time of high wind power generation and low power consumption can bring an even larger power cost reduction. It is noteworthy that, in commercial units with medium voltage, the power bill reduction could be even higher because the losses related to the transformer (conversion and conditioning) and transmission (wiring) were not considered. These losses occur because the building receives power with a voltage higher than that actually used.

\section{Conclusion}

This study showed economical feasibility to install vertical axis wind generators on roof buildings with adequate potential for private use of the generated energy. The optimization of the consumption could reduce the energy cost with the electric company. In medium power consumers the gains are even higher because of the eliminations of loss in the transformer and at transmission.

\section{Acknowledgement}

We thank PhD Maria Roseli Monteiro Callado for her assistance with the manuscript and www.nftranslation.com for its translation services.

\section{References}

[1] GRESNSPEC. "Domestic scale wind turbines $1-6 \mathrm{~kW}$ ", Available at: $<$ http://www.greenspec.co.uk/html/energy/windturbines.html $>$. [2] R. M. Callado. "Viabilidade da utilização de geradores eólicos na redução do custo de energia em condomínios prediais", Fortaleza (2009). Graduation Work (Eletronic Engineerig Program)-UNIFOR.

[3] SEINFRA - Secretaria da infraestrutura/ Governo do Ceará. "Atlas do potencial eólico do estado do Ceará", Camargo Schubert Engenharia Eólica, 2010, Available at: $<$ http://www.seinfra.ce.gov.br/index.php/downloads/category/3 -energia $>$.

[4] N. A. Rocha, D. J. Schultz, O.C. Amarante, M. V. B. Sugai, R. M. Bittencourt, "Estabilização sazonal da oferta de energia através da complementaridade entre os regimes hidrológico e eólico", in XV Seminário Nacional de Produção e Transmissão de Energia Elétrica, 1999. Available at: $<$ http://www.renovaveis.hpg.ig.com.br/temas/eolica/gpl17.pdf $>$ [5] Greenmaster Energy Technology (Shanghai) Co Ltd. "Revolutional V - series Wind turbine for the built-up enveronment with turbulence. Vertical axis wind turbine Wind turbine, windmaster", 2009, Available at:

$<$ http://www.greenmasterinc.com/index/mc/vawt.htm $>$.

[6] KINO ELETRICS CO. LTD., Available at: < http://www.tradett.com/companies/u35112>. Copia 24 nov. 2009. E-mail para Rômulo Monteiro Callado (zwb2908@zzkino.com). 